\title{
Seroprevalence of Human Cytomegalovirus in Pregnant Women in the Asir Region, Kingdom of Saudi Arabia
}

\author{
Mohammed K. Almaghrabi ${ }^{a} \quad$ Ali Dafer Alwadei $^{b} \quad$ Nawaf M. Alyahya ${ }^{b}$ \\ Fadaa M. Alotaibi ${ }^{b}$ Ahmad Hussain Alqahtani ${ }^{b}$ Khalid A. Alahmarib \\ Mohammad Salem Alqahtani ${ }^{\mathrm{b}} \quad$ Ahmad Saeed Alayed $^{\mathrm{b}}$ Riyad Moosa ${ }^{\mathrm{b}}$ \\ Abdelwahid S. Ali ${ }^{\mathrm{b}}$ \\ ${ }^{a}$ Department of Microbiology and Clinical Parasitology, King Khalid University, Abha, Kingdom of Saudi Arabia; \\ ${ }^{b}$ College of Medicine, King Khalid University, Abha, Kingdom of Saudi Arabia
}

\section{Keywords}

Human cytomegalovirus infection $\cdot \mathrm{HCMV} \cdot \lg \mathrm{G} \cdot$ Saudi

Arabia $\cdot$ Seroprevalence $\cdot$ Pregnant women

\section{Abstract}

Background: Human cytomegalovirus (HCMV) infection spreads easily by interpersonal contact. Objective: This study determined the prevalence of seropositivity of cytomegalovirus immunoglobulin $\mathrm{G}(\mathrm{lgG})$ in the Asir Region, Kingdom of Saudi Arabia. Methods: The study evaluated the seropositivity for cytomegalovirus-specific IgG in $460 \mathrm{fe-}$ males. Collected samples were processed and tested using enzyme-linked immunosorbent assay and specific HCMV IgG. Results: The study showed that all the respondents aged 15-20 years were seropositive for the HCMV. HCMV seropositive status was recorded in $99.2 \%$ of the older patients ( $>40$ years of age). In the remaining age groups, the rate of seropositivity ranged from 95.7 (age range 20-25 years) to $98.9 \%$ (age range 30 years). Conclusions: In all age groups of females tested, the prevalence of seropositive for HCMV was high, i.e., in the range of $95.7-100 \%$.

(c) 2020 The Author(s)

Published by S. Karger AG, Basel

\section{KARGER}

karger@karger.com www.karger.com/int (c) 2020 The Author(s) Karger
Published by S. Karger AG, Basel Open access
This article is licensed under the Creative Commons AttributionNonCommercial-NoDerivatives 4.0 International License (CC BYNC-ND) (http://www.karger.com/Services/OpenAccessLicense). Usage and distribution for commercial purposes as well as any distribution of modified material requires written permission.

\section{Introduction}

Human cytomegalovirus (HCMV), formally called Human betaherpesvirus 5, is abundant, and is 1 of 8 herpesviruses that routinely infect only humans [1]. It is also recognized as the common cause of congenital infections among newborns [1]. The major prevalence of the virus is observed in developing countries, accounting for $70 \%$ of cases [2]. The International Forum of Infectious diseases [3] has documented that the disease spreads by close interpersonal contact via body fluids like the saliva, blood, genital secretions, urine, and breast milk, or through the placenta of a pregnant woman. This virus has a lifelong latency in the cells of the premature myeloid lineage, particularly monocytes and granulocytes $[4,5]$. In children, infected saliva is the most common cause of HCMV infection. Sexual activity is the primary means of HCMV transmission among pregnant women and adolescents. Blood transfusion and organ transplantation can also transmit HCMV. Most studies confirm that seroprevalence is higher in non-whites and in individuals with a low socioeconomic status $[6,7]$. HCMV transmission of a new or reactivated latent infection may

Mohammed K. Almaghrabi

Department of Microbiology and Clinical Parasitology King Khalid University

Guraiger, Abha 62529 (Saudi Arabia)

malmaghrabi@kku.edu.sa 
Table 1. Age distribution in relation to HCMV seropositive status of patients at antenatal care clinics between 15 October 2014 and 15 January 2017

\begin{tabular}{lllr}
\hline Age, years & $\begin{array}{l}\text { Number } \\
\text { of patients }\end{array}$ & $\begin{array}{l}\text { Number of } \\
\text { seropositives }\end{array}$ & $\begin{array}{l}\text { Seroprevalence } \\
\text { of HCMV, \% } \\
(95 \% \text { CI) }\end{array}$ \\
\hline $15-20$ & $12(2.6 \%)$ & 12 & $100.0(99-100)$ \\
$21-25$ & $69(15.0 \%)$ & 66 & $95.7(91-100)$ \\
$26-30$ & $93(20.2 \%)$ & 93 & $100.0(98-100)$ \\
$31-35$ & $89(19.3 \%)$ & 88 & $98.9(97-100)$ \\
$36-40$ & $74(16.1 \%)$ & 73 & $98.6(96-100)$ \\
$>40$ & $123(26.7 \%)$ & 122 & $99.2(98-100)$ \\
\hline
\end{tabular}

Range 15-92

Mean \pm SD $\quad 34.9 \pm 11.8$

occur at any level of gestation, leading to congenital HCMV [8].

HCMV has a profound impact on the human body and can prevail for a long time. HCMV can lead to severe sickness such as fever, liver disease, pneumonitis, abdominal pain, diarrhea, and mononucleosis in healthy individuals $[9,10]$. As a response to HCMV, immunoglobulin $\mathrm{M}$ ( $\operatorname{IgM})$, a primary antibody, is produced in healthy individuals. When HCMV prevails for longer, i.e., $\geq 2$ weeks, the secondary antibody IgG is elicited. Among pregnant women, the risk associated with congenital infections is profound in the initial stages of infection, accounting for $40 \%$ in comparison to those occurring due to reinfection or reactivation of the disease [3].

In the southeastern region of Saudi Arabia, IgG directed against HCMV is present in about $78.4 \%$ of females. Anti-HCMV IgG increases when linked with hemodialysis $[11,12]$. Various studies have reported a high prevalence of HCMV among pregnant women due to the occurrence of previous infections [1,3-5]. A low rate of HCMV seroprevalence is observed in pregnant women in developed countries like France, Australia, Poland, and Belgium, but a high rate is reported in developing countries like Sudan, Egypt, Turkey, India, and Saudi Arabia [13]. To our knowledge, so far, no study has been made on the prevalence of HCMV seropositivity in the Asir Region. The work presented here fills this gap by determining the prevalence of seropositivity of IgG specific for HCMV among females attending antenatal care clinics in the Asir Region, Kingdom of Saudi Arabia.

\section{Materials and Methods}

\section{Sample Collection}

Four hundred and sixty women were randomly recruited for the study. The study population comprised female patients attending antenatal care clinics in the Asir Region. Samples were collected from women from different age groups, starting at the age of 15 years. About $5-10 \mathrm{~mL}$ of venous blood was drawn into plain tubes and allowed to clot at room temperature. Serum from each sample was separated by centrifugation at $10,000 \mathrm{~g}$. Subsequently, separated sera were distributed into vials and stored at $-20^{\circ} \mathrm{C}$ for further processing. The body units were used and calculated as shown below. Results were expressed as relative units/mL (RU) (optical density [OD]) by means of the following formula:

$\mathrm{RU}=\mathrm{OD}$ of sera at $450 \mathrm{~nm} \times 100 /$ mean positive control $\mathrm{OD}$ of sera at $450 \mathrm{~nm}$.

\section{Sample Testing by ELISA}

Serum samples were screened for anti-cytomegalovirus IgG, using commercially available kits (Human Co., Germany [cat. 51203]). Indirect ELISA was used to analyze the collected samples. The procedure and the evaluation and interpretation of the results strictly followed the description given by the manufacturer. Positive and negative controls, along with diluted serum samples (1: 101), were added into ELISA-plate coated wells (1 well was used as a blank). The samples and controls were incubated for $30 \mathrm{~min}$ at room temperature. At the end of the incubation period, the wells were washed manually 4 times using $350 \mu \mathrm{L}$ diluted washing buffer (1:20). Then, $100 \mu \mathrm{L}$ of the anti-IgG conjugate was added to all wells except the blank, and the plate was incubated for $30 \mathrm{~min}$ at room temperature. Wells were then washed 5 times as described before, and $100 \mu \mathrm{L}$ of substrate solution was added to all wells. Incubation took place for $15 \mathrm{~min}$ at room temperature. The reaction was stopped by the addition of $100 \mu \mathrm{L}$ of stop solution to all wells, and the absorbance was measured at a dual wavelength of 450 and $630 \mathrm{~nm}$ using an ELISA reader (Humareader, Wiesbaden, Germany). The cut-off value (COV) for the test was calculated using the formula:

$\mathrm{COV}=$ mean negative control $+(0.1 \times$ mean positive control $)$.

The result was considered positive for anti-CMV IgG if the absorbance of the sample was $\geq \mathrm{COV}+15 \%$. The result of the positive samples was reported as RU with the formula:

$\mathrm{RU}=$ absorbance value of sera $\times 100 /$ mean positive control.

A correlation between patients' age and the prevalence of HCMV antibodies was calculated.

\section{Results}

Most participants, i.e., 93 and $89 \%$, belonged to the age groups $26-30$ years and $31-35$ years, respectively. Moreover, $74 \%$ of the participants were $36-40$ years of age, and 
only $40 \%$ were $21-25$ years of age. None of the participants in the age groups 15-20 years and 21-25 years had a bachelor's degree. The results also showed that all the tested patients older than 20 years had given birth $\geq 1$ time.

Most of the tested participants were older than 40 years and only $2.6 \%$ were $15-20$ years of age (Table 1 ). Only $2.6 \%$ of the study sample were $15-20$ years old and $26.7 \%$ were older than 45 years. The results of the ELISA test indicated that the majority $(98.7 \%)$ of the tested females were seropositive for HCMV. The remaining 1.3\% were either seronegative or equivocal (Table 1; Fig. 1).

It is noteworthy that $100 \%$ of those aged $15-20$ years were seropositive for HCMV. Patients aged 25-30 years were completely HCMV seropositive. HCMV-seropositive status was recorded in $99.2 \%$ of older patients (i.e., older than 40 years). In addition, $95.7 \%$ of patients aged 20-25 years were seropositive and up to $98.9 \%$ of patients older than 30 years had a similar status (Table 1).

All patients aged 15-20 years were seropositive for HCMV (95\% confidence interval [CI] 99-100\%) similar to what was observed for those aged 25-30 years and those older than 40 years. The patients aged $20-25$ years ranged from 91 to $100 \%$ for HCMV seropositivity (Table 1). There was a positive correlation between age and prevalence of HCMV antibodies (correlation coefficient $r=$ $0.016 ; p<0.01)$ in the tested patients.

\section{Discussion}

The rate of seropositivity for anti-HCMV IgG was very high in females attending antenatal care clinics in the Asir Region, Kingdom of Saudi Arabia. The study population included women who had no previous history of HCMV infection. The proportion of HCMV IgG-seropositive individuals ranged from 95.7 to $100 \%$. This rate of HCMV seropositivity has been reported as the highest in the country. Kenneson and Cannon [14] reported a rate of HCMV seropositivity of $78.4 \%$, lower than our result.

Our findings suggest that a correlation exists between HCMV prevalence and oxygen level. Our study has demonstrated that HCMV occurs at high altitudes where the low oxygen level leads to an increase in cytotrophoblasts. In contrast, Eisen et al. [15] stated that high altitude is a factor that can reduce the prevalence of HCMV.

The most prominent reason for the high rate of $\mathrm{HCMV}$ seropositivity is the closeness of contact within the population. These contacts are more frequent and closer in the Asir Region than in other parts of the country; in the Jazan Region, it was reported to be $93.10 \%$ [2].

Prevalence of Human Cytomegalovirus

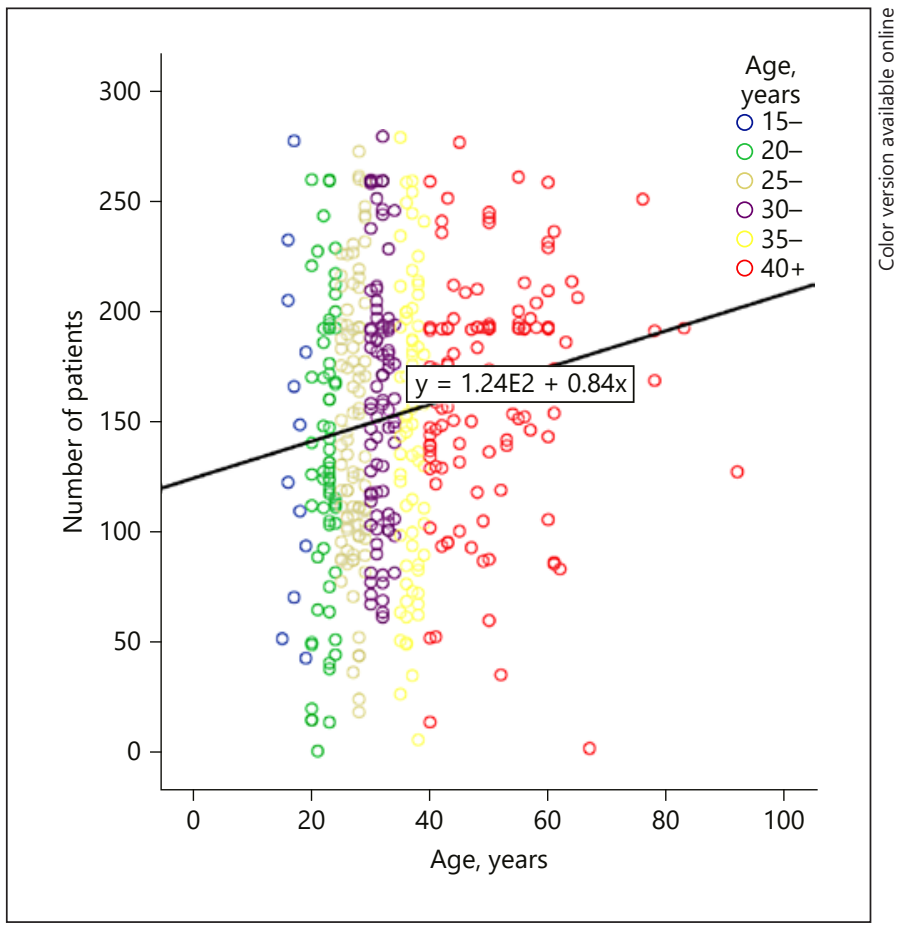

Fig. 1. Correlation between patients' age and the number of HCMV antibodies in patients at the antenatal care clinics.

Another reason for the increased occurrence of HCMV may be the increase in placental weight, highlighting the need to introduce measures for the development of a more extensive peripheral villous tree [16].

In this study, it was necessary to screen blood transfusion recipients for HCMV positivity. The prevalence of seropositivity for anti-HCMV IgG was high in all age groups of the females tested (range 95.7-100\%). After the screening, only those who were negative for HCMV needed to receive HCMV-free blood or blood products. This refers to young patients who were not exposed to the virus. Immunocompromised patients seropositive for HCMV also need an HCMV-free blood transfusion. Our findings also pointed to a weak correlation between age and the prevalence of HCMV antibodies, in agreement with the findings of Zhang et al. [17] in China.

As stated above, HCMV is in abundant circulation worldwide. This herpes virus is transmitted by close interpersonal contact, sexual transmission, blood transfusion, and organ transplantation. It has a life-long latency in monocytes and granulocytes.

$\mathrm{HCMV}$ is considered to be the most common cause of congenital viral disease in developed countries, in association with hearing loss $[18,19]$. The seropositivity rate 
of HCMV is low in developed countries and high in developing countries. Congenital HCMV occurrence is about $0.2-2.0 \%$ of all pregnancies. In the USA, approximately 20,000-40,000 infants per year are born with congenital HCMV infection [20]. The prevalence of HCMV antibodies in adults varies across the globe, with the lowest rate in Europe, parts of North America, and Australia, and higher rates in Africa and Asia [2, 3, 13].

Our findings indicate that estimating seroprevalence in pregnant women is necessary for determining the transmission of congenital CMV, which can impact neonates. Similarly, the findings of Yamamoto et al. [21] showed that CMV prevalence in pregnant women was similar irrespective of age group, i.e., in women aged 1246 years. This suggests that the majority of CMV infections develop in infancy or childhood because the increase in CMV seroprevalence is found in women at an early age [22]. Another study assessing seroprevalence in a nationally representative sample showed that $50 \%$ of women of childbearing age are vulnerable for the development of primary CMV infection during the gestational period [22]. CMV screening during pregnancy is not considered the best strategy to prevent congenital infection. Screening of pregnant women for CMV is not recommended due to the absence of treatment for intrauterine CMV infection, and this remains a controversial issue.

Similar to our study results, Zhang et al. [17] showed that the active maternal CMV infection during pregnancy might be a risk factor for adverse pregnancy and neonatal outcomes among women with a greater prevalence of latent CMV infection. The maternal rate of presumed recurrent infection is a major reason for most of the cases of congenital infection. This emphasizes that pregnant women should be screened for active HCMV infection in countries with a high rate of anti-HMCV IgG seroprevalence.

Kuessel et al. [23] were successful in identifying predictors of maternal CMV serostatus in the early period of pregnancy through the development of a risk-predicting model based on baseline epidemiological characteristics. Their analysis indicated that most of the mothers were seropositive for HCMV IgG, and that only a very limited population was seronegative. The identification of the HCMV IgG was common in most middle-aged women. A positive relationship between antibodies and HCMV prevalence was also identified. With respect to the given factors, the formation of appropriate health care plans was highly recommended for developing countries. Educational programs must be arranged for pregnant women to provide them with information regarding HCMV and preventive measures that may help to control the develop- ment and transmission of the disease. Besides this, guidance should be provided to the women concerning the adequate age for pregnancy and the hygienic standards.

Since our study was restricted to a certain sample size, some limitations were present. We did not determine the $\mathrm{CMV}$ seroprevalence in a representative, age-stratified sample of unselected pregnant women. This pinpoints the need for further investigations while considering other important factors associated with the prevalence of the disease.

\section{Acknowledgment}

The authors would like to acknowledge the microbiology staff at the laboratory of Asir Central Hospital for their cooperation in supplying these isolates to our laboratory.

\section{Statement of Ethics}

The study was approved by the Research Ethics Committee, College of Medicine, King Khalid University, Abha, Saudi Arabia. Informed consent was taken from the participants before starting the procedures.

\section{Disclosure Statement}

The authors declare no conflicts of interest.

\section{Funding Sources}

This research did not receive any specific grant from funding agencies in the public, commercial, or not-for-profit sectors.

\section{Author Contributions}

M.K.A., A.D.A., and N.M.A. were responsible for the conception, design. and research. M.K.A., F.M.A., A.H.A., K.A.A., M.S.A., and A.S. Alayed coordinated the analysis. M.K.A. and A.S. Ali were responsible for the conclusive and final remarks. M.K.A. did the final approval along with research correspondence.

References

Almaghrabi et al.
1 Read C, Schauflinger M, Nikolaenko D, Walther P, von Einem J. Regulation of human cytomegalovirus secondary envelopment by a C-terminal tetra-lysine motif in pUL71. J Virol. 2019 Jun;93(13):e02244-18.

2 Bakri M, Agag A, Alnemri A, Hobani Y, Najmi A, Alaamri AI, et al. Serostatus of cytomegalovirus among population, Jazan region, Saudi Arabia. Sky J Microbiol Res. 2016;4:52-9. 
3 International Forum of Infectious diseases [Internet]. International Society of Antimicrobial Chemotherapy [cited March 2019]. Available from: https://www.ifid2019.org/ IFID2019Kitabi.pdf

4 Elder E, Sinclair J. HCMV latency: what regulates the regulators? Med Microbiol Immunol (Berl). 2019 Aug;208:431-8.

5 Collins-McMillen D, Buehler J, Peppenelli M, Goodrum F. Molecular determinants and the regulation of human cytomegalovirus latency and reactivation. Viruses. 2018 Aug;10(8): 444.

6 Almoaish MA, Al-Shamahy HA, Al-Hajj MM, Dainamah SM, Al-Madhaji AG. Prevalence of cytomegalovirus IgG antibodies, potential risk factors and awareness of congenital cytomegalovirus among female doctors. Universal J Pharm Res. 2018. DOI: 10.22270/ ujpr.v3i5.199.

7 Zuhair M, Smit GS, Wallis G, Jabbar F, Smith C, Devleesschauwer B, et al. Estimation of the worldwide seroprevalence of cytomegalovirus: A systematic review and meta-analysis. Rev Med Virol. 2019 May;29(3):e2034.

8 Krmpotić A, Podlech J, Reddehase MJ, Britt WJ, Jonjić S. Role of antibodies in confining cytomegalovirus after reactivation from latency: three decades' résumé. Med Microbiol Immunol (Berl). 2019 Aug;208(3-4):415-29.

9 Bernstein S, Meskey T, Helm K, Miller J, Foulke G, Chung C. Localized cutaneous sclerodermoid changes secondary to human cytomegalovirus infection: an uncommon presentation in an immunocompetent host. JAAD Case Rep. 2016 Mar;2(2):119-21.
10 Hasannia T, Moosavi Movahed SM, Vakili R, Rafatpanah H, Hekmat R, Valizadeh N, et al. Active CMV and EBV infections in renal transplant recipients with unexplained fever and elevated serum creatinine. Ren Fail. 2016 Oct;38(9):1418-24.

11 Waseem H, Ali J, Jamil SU, Ali A, Jameel S. Seroprevalence of Cytomegalovirus among pregnant women in Islamabad, Pakistan. JEZS. 2017;5(2):1788-91.

12 Cobelens F, Nagelkerke N, Fletcher H. The convergent epidemiology of tuberculosis and human cytomegalovirus infection. F1000 Res. 2018 Mar;7:280.

13 Alghalibi SM, Abdullah QY, Al-Arnoot S, AlThobhani A. Seroprevalence of Cytomegalovirus among Pregnant Women in Hodeidah City, Yemen. J Hum Virol Retrovirol. 2016; 3(5):00106

14 Kenneson A, Cannon MJ. Review and metaanalysis of the epidemiology of congenital cytomegalovirus (CMV) infection. Rev Med Virol. 2007 Jul-Aug;17(4):253-76.

15 Eisen S, Pealing L, Aldridge RW, Siedner MJ, Necochea A, Leybell I, et al. Effects of ascent to high altitude on human antimycobacterial immunity. PLoS One. 2013 Sep; 8(9):e74220.

16 Pereira L, Petitt M, Tabata T. Cytomegalovirus infection and antibody protection of the developing placenta. Clin Infect Dis. 2013 Dec;57(suppl 4):S174-7.
17 Zhang S, Hu L, Chen J, Xu B, Zhou YH, Hu Y. Cytomegalovirus seroprevalence in pregnant women and association with adverse pregnancy/neonatal outcomes in Jiangsu Province, China. PLoS One.2014Sep;9(9):e107645.

18 Korver AM, Smith RJ, Van Camp G, Schleiss MR, Bitner-Glindzicz MA, Lustig LR, et al. Congenital hearing loss. Nat Rev Dis Primers. 2017 Jan;3(1): 16094.

19 Pati S, Novak Z, Boppana S, Fowler K, Ross S. [Internet] Cytomegalovirus Shedding in Saliva and Hearing Loss in Congenital Cytomegalovirus (CMV) Infection [cited $24 \mathrm{Oct}$ 2016]. Available from: https://doi.org/https:// doi.org/10.1093/ofid/ofw172.517.

20 Hughes BL, Gyamfi-Bannerman C; Society for Maternal-Fetal Medicine (SMFM). Diagnosis and antenatal management of congenital cytomegalovirus infection. Am J Obstet Gynecol. 2016 Jun;214(6):B5-11.

21 Yamamoto AY, Castellucci RA, Aragon DC Mussi-Pinhata MM. Early high CMV seroprevalence in pregnant women from a population with a high rate of congenital infection. Epidemiol Infect. 2013 Oct;141(10):2187-91.

22 Lachmann $\mathrm{R}$, Loenenbach $\mathrm{A}$, Waterboer $\mathrm{T}$, Brenner N, Pawlita M, Michel A, et al. Cytomegalovirus (CMV) seroprevalence in the adult population of Germany. PLoS One. 2018 Jul;13(7):e0200267.

23 Kuessel L, Husslein H, Marschalek J, Brunner J, Ristl R, Popow-Kraupp T, et al. Prediction of maternal cytomegalovirus serostatus in early pregnancy: a retrospective analysis in Western Europe. PLoS One. 2015 Dec; 10(12):e0145470 